\title{
Evaluation of the Effect of Information and Communication Technology on Creativity of Employees of Public Organizations (Case Study: Office of Telecommunications of the County of Semnan)
}

\author{
Dr. Amir Hossein Amir Khani \\ Assistant professor, Payamenoor University, Iran \\ Seyed Ehsan Tabatabaei \\ Yazadan Parvari
}

MA, Department of management, Tehran West Branch, Payamenoor University, Iran

Doi:10.5901/mjss.2016.v7n3s2p32

\begin{abstract}
Among organizational creativity models, the variables of increased knowledge and awareness of personnel, their professional development, their capacity for innovation and self-control is studied. The purpose of this research is identification of the relationship between information and communication technology with employee creativity in the telecommunication office of the county of Semnan. Therefore, this study purpose wise was an applied research and considering that it described the present situation, it was descriptive. Statistical population of the research included all employees and directors of the office of telecommunications in the county of Semnan, where using the Cochrane sample size formula, 380 individuals were selected to participate in the study. Data from this research collected by way of standard questionnaires, where the validity was confirmed by considering opinion of professors and experts and the reliability was confirmed using the Cronbach's alpha coefficient. Statistical analysis was performed using the Klomogorov-Smirnov and Pearson's correlation coefficient tests, partialleast squaremethod and structural equation modeling with the help of LISREL software. Results of the research showed that positive correlation exists between information and communication technology and the variables of organizational creativity, where ultimately, with consideration of research findings, suggestions are made for promotion of employee creativity with regards to information and communication technology.
\end{abstract}

Keywords: Information and Communication Technology, Organizational Creativity

\section{Introduction}

One of the most important challenges in the domain of organizational behavior in this era is rapid progress and changes in the area of information technology. Based on scientific opinions of most scientists, application of information technology leads to increased knowledge and awareness in employees and enriches the content of occupations (Sarafizadeh, 2009).

Use of information technology in addition to influencing the nature of work and its environment, changes the way organizations compete. Information technology has led to development and improvement of organizations' internal information, decreased internal expenditures and facilitation of production. Decreased cost has even provided opportunity for profiting at lower prices of products. By fast action in getting the product to the market access to profits is achieved more rapidly. Information technology helps the process of marketing and sale and rapidity of action in marketing particularly in cases where new products lead to decreased prices and obliteration of opportunities is enhanced (Zargar, Mahmoud, 2009). The result is that information technology becomes a tool for data collection and processing and their transformation into information. Therefore, application of information technology in organizations is rapidly advancing and organizations need to use information technology for reaching their goals and objectives. On the other hand, employees are also important resources for organizations that perform most of their tasks with the information gained form information technology. Solving problems is important because with knowledge about the main angles of information technology and its correct application, creativity in employees can be increased greatly and ultimately company advancement can be achieved. Promotion of creativity by training motivated and able personnel provides the directors with the opportunity to act appropriately with respect to dynamicism of the competitive environment and leads to 
competitive advantage of the organization. Rapid growth of technology influences all aspects of organizations in a way. Such rapid growth leads to change in the nature of tasks and computers, robots and totally automatic equipment have replaced routine jobs. These instruments have created major changes in the kind of skills needed by individuals and members of organizations (Orai, Yazdani 2010). The purpose of this research was evaluation of effect of information technology on creativity of employees in the telecommunication department and following that formulation of programs to improve and enrich organizational occupations with management and correct use of information technology and utilization of employee creativity to advance organizational goals. Therefore, with consideration of the fact that up to now little research has been performed in Iran that evaluates the relationship between these variables, the researcher sought to examine and evaluate this relationship.

\section{Theoretical Statement of the Research}

\subsection{Information and Communication Technology}

Information technology consists of all techniques and tools utilized for improvement and support of active systems with focus on information and knowledge and also study, design, expansion, implementation, maintenance and management of information systems based on computers and particularly soft and hard ware computer applications (Fahimi, 2009).

Information technology has provided the opportunity to connect various computers by way of equipment, tools and communication media to each other and exchange information and knowledge. In the traditional method, users took advantage of the computer for preparation of documents or a specific applied program such as accounting and information exchange between employees was through mail or phone numbers (Sarafizadeh, 2009). Additionally, information technology constitutes of application of computers and other technology in working with information. Here, any kind of technology inclusive of any instrument or technique is under consideration. Generally and incorrectly, in information technology, working with information only by way of computer technology, communication and related products has been considered. It should be noted that the term technology includes study of the method of use of human constructs in reaching goals and objectives such as provision of products and services. This term does not just refer to human made products (Kline, 2012).

\subsection{Conceptual Definition of Creativity}

Creativity is consequential and evolutionary changes in human thought and intellect such that it involves the ability to combine previous factors and new methods. In other words, creativity is complete application of cognitive abilities in production of a new thought, solution or new concept relative to the creative individual (Zareimatin, 2004). Therefore, creativity is the process of sensing existing issues or deficiencies, hypothesizing about solution of problems and omission of deficiencies and testing hypotheses, reevaluation and retesting them and ultimately transferring the results to others (Luthans, 2009).

\section{Research Hypotheses}

\subsection{Main Hypothesis}

Information and communication technology has positive influence on creativity of employees of the office of telecommunications in the county of Semnan.

\subsection{Minor Hypotheses}

1. Information and communication technology has positive influence on increased knowledge and awareness of employees of the office of telecommunications of the county of Semnan.

2. Information and communication technology has positive influence on professional development of employees of the office of telecommunications of the county of Semnan.

3. Information and communication technology has positive influence on innovative capabilities of employees of the office of telecommunications of the county of Semnan.

4. Information and communication technology has positive influence on self control capabilities of employees of the office of telecommunications of the county of Semnan. 


\subsection{Method of Research}

Since this research has the purpose of using existing knowledge for evaluation of the office of telecommunications of Semnan and also helps managers in decision making, it is an applied research in purpose. Based on nature and method, it is a descriptive and survey study. Methods of data collection in this research are two in kind library research and field study. Regarding data collection related to the topic literature and research background, library investigation was used for collection of information and for confirmation or rejection of research hypotheses, field study was used. In this research, for primary data collection questionnaire was used. Two questionnaires were used in this research:

Knowledge of information technology questionnaire

Creativity of organization employees' questionnaire

The knowledge of information technology questionnaire uses 15 tangible variables (questions). This questionnaire has been prepared based on Master's Degree dissertation of Fatemeh Asghari (Guide: Hassan Forati) in the office of well fare of Semnan. The considered questionnaire has been culture oriented with adaptation and moderation. Employee creativity questionnaire also has 4 main factors (implicit variables) and 20 items (tangible variables). The dimensions of the employee creativity questionnaire include: increased knowledge and awareness of employees, their professional development, their innovative capabilities and self control. This questionnaire has been designed based on the organizational creativity scale by Torrance. The Cronbach's alpha coefficient for organizational creativity questionnaire was 0/955 and for information technology questionnaire it was calculated at 0/871. Therefore, reliabilities of the questionnaires were evaluated to be appropriate. Statistical population of this research constituted of all employees of the telecommunication office of the county of Semnan. For determination of sample size, the Cochrane formula was used. Considering the calculations performed, 380 individuals were estimated as appropriate for the statistical sample size. Also, overall the research hypotheses were tested using structural equation modeling. For this purpose, initially the data was tested for normalcy. Ultimately, the model related to the main and minor hypotheses was implemented. Structural equation modeling was performed with the help of LISREL version 8.8 software.

\section{Research Findings}

\subsection{Test of normalcy of the data}

Based on results shown in Table (1), in all instances the significance level obtained was higher than 0/05. Therefore, there is no reason for rejecting the hypothesis. In other words, the distribution of the data evaluated in every dimension is normal. Therefore, parametric tests can be used.

Table (1). Test of normalcy of the data

\begin{tabular}{|l|c|c|c|c|c|}
\hline & $\begin{array}{c}\text { Increased knowledge and } \\
\text { awareness of employees }\end{array}$ & $\begin{array}{c}\text { Professional development } \\
\text { of employees }\end{array}$ & $\begin{array}{c}\text { Innovative capabilities of } \\
\text { employees }\end{array}$ & $\begin{array}{c}\text { Self } \\
\text { controlling }\end{array}$ & $\begin{array}{c}\text { Information } \\
\text { technology }\end{array}$ \\
\hline $\mathrm{N}$ & 380 & 380 & 380 & 380 & 380 \\
\hline Mean & $3 / 792$ & $3 / 408$ & $3 / 461$ & $3 / 184$ & $3 / 718$ \\
\hline Standard deviation & $0 / 741$ & $1 / 017$ & $1 / 058$ & $1 / 132$ & $0 / 711$ \\
\hline Kolmogorov-Smirnov & $1 / 999$ & $1 / 566$ & $1 / 530$ & $1 / 361$ & $1 / 084$ \\
\hline Significance level & $0 / 745$ & $0 / 148$ & $0 / 186$ & $0 / 491$ & $0 / 191$ \\
\hline
\end{tabular}

\subsection{Test of Research Hypotheses}

\subsubsection{Test of the first minor hypothesis}

Information and communication technology has positive influence on increased knowledge and awareness of employees of the office of telecommunications of the county of Semnan.

Considering Table (2), the standard factor load between the two factors of information technology and knowledge and awareness of employees was obtained to be 0/69. The value for the t statistics was 10/05 which was higher than $1 / 96$ and shows that meaningful correlation exists. Therefore, with a confidence of 95 percent, information and communication technology has positive influence on increased knowledge and awareness of employees of the telecommunication office of the county of Semnan. 


\subsubsection{Test of the second minor hypothesis}

Information and communication technology has positive influence on professional development of employees of the office of telecommunications of the county of Semnan.

Considering Table (2), the standard factor load between the two factors of information technology and knowledge and awareness of employees was obtained to be 0/87. The value for the t statistics was $12 / 80$ which was higher than $1 / 96$ and shows that meaningful correlation exists. Therefore, with a confidence of 95 percent, information and communication technology has positive influence on professional development of employees of the telecommunication office of the county of Semnan.

\subsubsection{Test of the third minor hypothesis}

Information and communication technology has positive influence on innovative capabilities of employees of the office of telecommunications of the county of Semnan.

Considering Table (2), the standard factor load between the two factors of information technology and knowledge and awareness of employees was obtained to be 0/88. The value for the t statistics was 15/54 which was higher than $1 / 96$ and shows that meaningful correlation exists. Therefore, with a confidence of 95 percent, information and communication technology has positive influence on innovation capability of employees of the telecommunication office of the county of Semnan.

\subsubsection{Test of the fourth minor hypothesis}

Information and communication technology has positive influence on self control capabilities of employees of the office of telecommunications of the county of Semnan.

Considering Table (2), the standard factor load between the two factors of information technology and knowledge and awareness of employees was obtained to be 0/84. The value for the t statistics was 14/32 which was higher than $1 / 96$ and shows that meaningful correlation exists. Therefore, with a confidence of 95 percent, information and communication technology has positive influence on self control of employees of the telecommunication office of the county of Semnan.

Table (2). Standard factor load of the relationship between increased knowledge and awareness of employees and information technology

\begin{tabular}{|l|c|c|}
\hline Variables & Standard factor load & t statistics \\
\hline Increased knowledge and awareness and information technology & $0 / 69$ & $10 / 05$ \\
\hline Professional development of employees and information technology & $0 / 87$ & $12 / 80$ \\
\hline Innovation capability of employees and information technology & $0 / 88$ & $15 / 54$ \\
\hline Self control of employees and information technology & $0 / 84$ & $14 / 32$ \\
\hline
\end{tabular}

Diagram (1). Standard factor load of test of research hypotheses

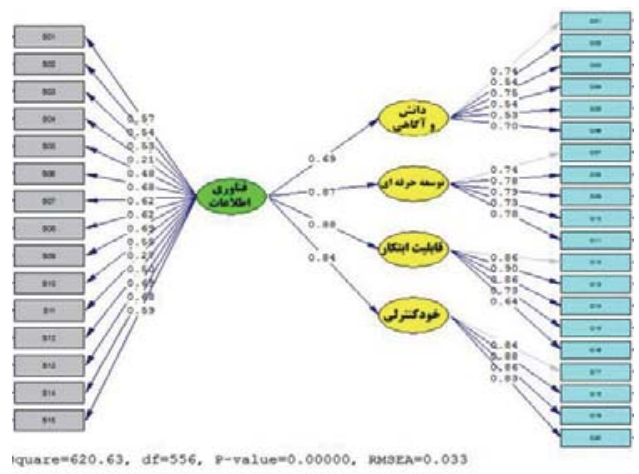


Diagram (2).T-value statistics for test of research hypotheses

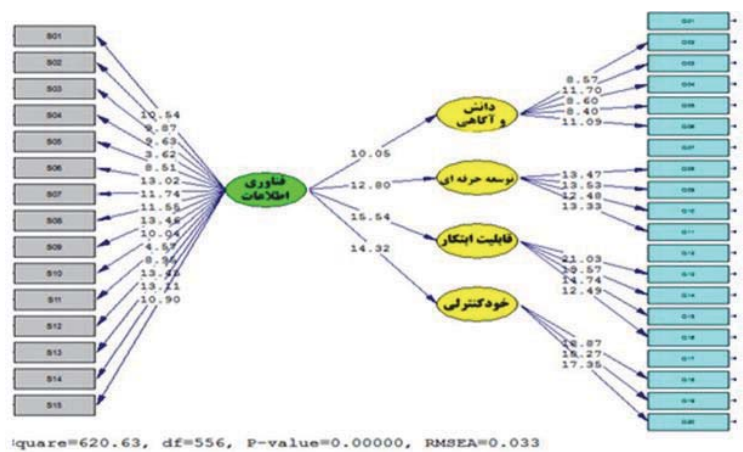

\section{Model Goodness of Fit}

The structural model has been saturated in three stages. Fit indices show desired values. Normalized Chi-square is also $1 / 116$ which is located in the acceptable range of 1 to 5 . Therefore, the structural model has good fit.

$$
\frac{\chi^{2}}{d f}=\frac{620.63}{556}=1.116
$$

Additionally, since the fit index RSMEA is equal to 0/033 which is smaller than 0/05, the model has good fit. Other indices of good fit are also located in the acceptable range.

Table (3). Indices of goodness of fit of the structural equation for the minor hypotheses of the research

\begin{tabular}{lccccccc}
\hline Index of fit & SRMR & RMSEA & GFI & AGFI & NFI & NNFI & IFI \\
\hline Acceptable values & $<0 / 05$ & $<0 / 1$ & $>0 / 9$ & $>0 / 9$ & $>0 / 9$ & $>0 / 9$ & $0-1$ \\
Calculated values & $0 / 029$ & $0 / 033$ & $0 / 91$ & $0 / 96$ & $0 / 96$ & $0 / 98$ & $0 / 96$ \\
\hline
\end{tabular}

\section{Test of Main Hypothesis}

Information and communication technology has positive influence on creativity of employees of the telecommunication office in the county of Semnan. The standard factor load of information technology on employee creativity has been calculated to be 0/68 which is an acceptable value. The value for the test statistic (t-value) is also 10/45 which shows that this correlation is meaningful. Therefore, positive and meaningful correlation exists between «employee» creativity and «information technology».

Table (4). Standard factor load for the correlation between employee creativity and information technology

\begin{tabular}{|l|c|c|}
\hline Correlation & Standard factor load & t statistics \\
\hline Employee creativity and information technology & $0 / 68$ & $10 / 45$ \\
\hline
\end{tabular}




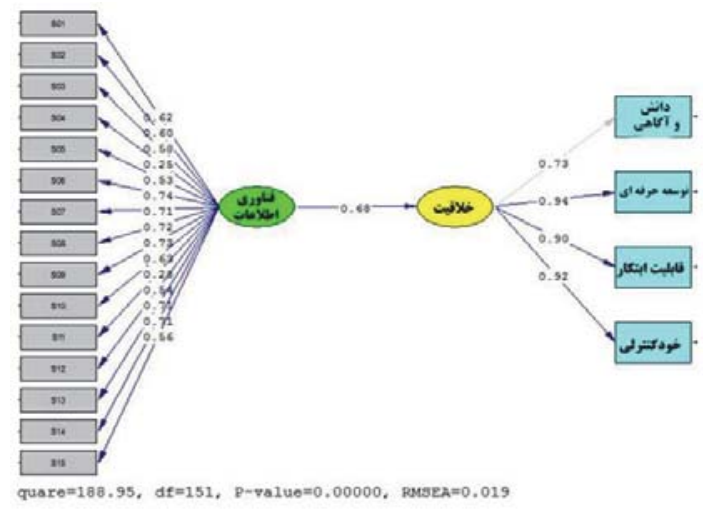

Diagram (3). T-value statistics for results of confirmation of the final research model

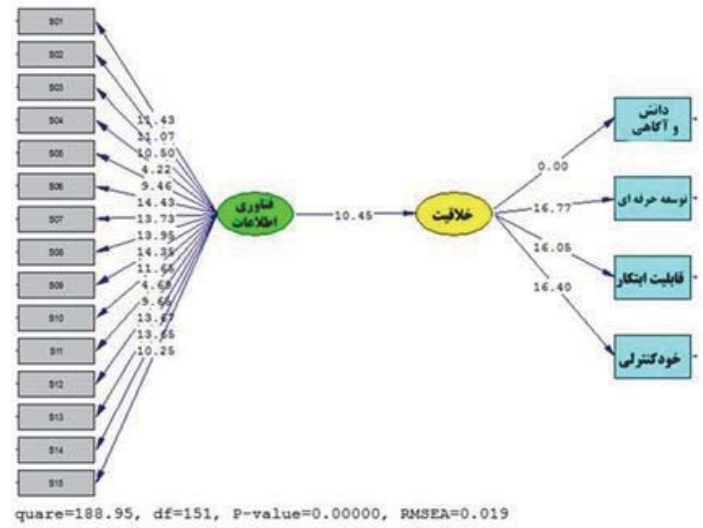

\section{Model Goodness of Fit}

The structural model has been saturated in two stages. Fit indices show desired values. Normalized Chi-square is also $1 / 251$ which is located in the acceptable range of 1 to 5 . Therefore, the structural model has good fit.

$$
\frac{\chi^{2}}{d f}=\frac{188.95}{151}=1.251
$$

Additionally, since the fit index RSMEA is equal to 0/019 which is smaller than 0/05, the model has good fit. Other indices of good fit are also located in the acceptable range.

Table (5). Indices of goodness of fit of the structural equation for the main hypotheses of the research

\begin{tabular}{lccccccc}
\hline Index of fit & SRMR & RMSEA & GFI & AGFI & NFI & NNFI & IFI \\
\hline Acceptable values & $<0 / 05$ & $<0 / 1$ & $>0 / 9$ & $>0 / 9$ & $>0 / 9$ & $>0 / 9$ & $0-1$ \\
Calculated values & $0 / 021$ & $0 / 019$ & $0 / 96$ & $0 / 96$ & $0 / 98$ & $0 / 98$ & $0 / 94$ \\
\hline
\end{tabular}

\section{Discussion of Results}

Considering the progress in information technology globally, there is increased necessity by the day for knowledge of and correct application of information technology in organizations. Performance of this research was important and necessary because we need to know to what extent information technology has been important in improvement of qualitative performance of employees such that with provision of appropriate context for creation of optimal communication and 
cooperation between members, advantages are gained for individuals and the organization. Results of the first hypothesis showed that with a confidence level of $95 \%$, information and communication technology has positive influence on increased knowledge and awareness of employees of the telecommunication office of the county of Semnan. This hypothesis is in line with and agrees with the research and opinions of Vares (2008) and Vatan and Kamroun (2008).

The results of the second hypothesis showed that with a confidence level of 95\% information and communication technology has positive influence on professional development of employees of the telecommunication department of the county of Semnan. This hypothesis is in line with and agrees with research and opinions of Sarafizadeh (2009), Scott and Jaffe (1991), Saj and Kaslovosky (2000), and Thomas and Volthus (1990). Results of the third hypothesis showed that with a confidence level of $95 \%$, information and communication technology has positive influence on innovation capability of employees of the telecommunication office of the county of Semnan. This hypothesis is in line with and agrees with research and opinions of Otarkhani (2008), Alex Osborn (1989), and Gilford (1959). Results of the fourth hypothesis showed that with a confidence level of $95 \%$, information and communication technology has positive influence on self control of employees of the office of telecommunications in the county of Semnan. This hypothesis is in line with and agrees with research and opinions of Goudarzi and Gaminian (2010), Porter (1962).

\section{Suggestions Based on Research Findings}

- With consideration of importance of establishment and profiting from information technology, it can be achieved with strategies such as evaluation of the possibility of holding educational sessions during service for employees electronically in the organization and formation of virtual during service classes and even holding educational programs via the internet.

- Considering that information technology enforces great expenses on the company, directors of organizations should in their comprehensive information technology program, accurately expand on economic issues and evaluate their consequences so they can ultimately select the best choice for their firm.

- Due to the increased role familiarity with information technology can play in enablement of organizational employees, it is recommended that case investigations be performed in this regard so by way of experience of other organizations in the matter of using information technology, awareness is gained for encouraging innovation in employees.

- Considering the rapid growth of information technology in various areas and increasing daily need and dependence on this technology, one of the important duties of managers in organizations is keeping the firm up to date with these changes, such that with least expenditure, best choices are made. The comprehensive information technology plan is a document in which after exert evaluations, initially the existing situation in the organization with the purpose of provision of all information needs in a global form and with the mission and outlook of the organization is explained, where it is suggested to firms to use this plan optimally.

- Emphasis is needed on teaching ICT skills to employees of the telecommunication office so they gain mastery and complete familiarity with information and communication technology such that directors can design appropriate plans for methods of profiting from ICT and for the growth of creativity.

- For promotion and improvement of the factor of use of IT tools in telecommunication office, it is suggested that employee access to the internet is desirably provided for. Additionally, electronic documentation management systems should be used for performance of office matters and data banks used for storage of information.

- To improve and promote human resources management factor in the telecommunication office, it is suggested that specialists with consideration of their field of study are placed in their real positions, directors create motivation in employees in endeavor to promote their knowledge and education level, sufficient opportunity is provided for employees to apply their knowledge in the work environment and also a comprehensive program for achievement of educational needs and development of all employees is prepared and implemented.

- Since the results show that application of IT in organizations due to expansion of knowledge and information of employees leads to importance and credibility of employee posts in society, it is suggested that organizations encourage personnel who use technology more commonly.

- We should endeavor to develop the thoughts and information of directors from their level of abilities, specialty and ideas in the job domain or in a related task so the blind and unknown field and gap between employees and directors are minimized. This issue, in addition to increasing level of mutual trust, in its place is one of the fundamental factors in delegation of matters, decisions and job roles in accord with interests, ability, experience and specialization of employees and improvement of working methods and qualitative and 
quantitative promotion of the domain of services and products.

- Change in physical conditions (ergonomics) and fluidity of work and occupational domain such that it leads to decreased and omission of anxiety, destructive stress and simplicity of performance and acceptance of difficult, hard, constant and unsuccessful responsibilities and adaptation of the personnel with the occupation at hand.

- Performance of effective programs, job rotation and enrichment, its standardization appropriate with existing conditions and requirements and level of interest, knowledge, specialization and efficiency of employees is extremely important in employee empowerment and improvement of effective communication chain between employees.

- Employees should by way of acquisition of modern occupation information and qualitative increase in product and service return help management in reaching important and strategic goals of the firm and establish a strong and standing bridge with their senior officials. Employees by way of use of modern and up to date knowledge and reengineering of methods of job performance and processes of work take action towards quantitative and qualitative increase in matters.

- Employees should endeavor to understand the reason for the organizations establishment and its path and spend effort with identification of opportunities and threats in the environment of the organization and understanding its goals to realize them. They should take action with regards to identification of methods of work and paths that improve the process of product and service provision among competitors. The organization should also mutually by way of expansion and development of this culture via presentation of needed training or its introduction with the purpose of expanding and deepening relations with senior managers take necessary steps.

- Encouragement of involving employees in tasks is based on the idea that people involved with a process are more knowledgeable about it compared to anyone else and it has been observed that these employees have higher motivation for optimizing their performance. Participation of employees for improvement of processes is a necessity.

- One of the important reasons in lack of participation and collaboration between individuals is lack of places (such as scientific and technology park) for participation or difficulty for individuals to gain access to them. The number of these locations in the country is very little. Additionally entrance into these locales is only possible through the company frame. Most of these places are allocated to big and well known companies who gain access to them based on their fame not based on innovation or qualification. Therefore, for entrance to these parks, fair rules should be set and it should be based on qualifications so one of the main substructures of innovation in these parks and at the macro level in cities and countries are strengthened.

- One of the main reasons for lack of interest of individuals to participate is confounding administrative regulations. If an individual has an idea who he or she wishes to share with the public, when he or she attempts to publish his or her idea, he or she needs to pass several administrative stages or seek multiple organizations and this issue can lead to disappointment. For resolution of this problem, stages for product registration and presentation should be decreased or even internet environment can be used for simplification of idea registration.

\section{References}

[In Persian]

Fahimi, Mehri (2009). Applications of IT.Journal of Management Studies, no29-30.

Gilford (1959). Components of creativity.Journal of Curricular Research, p69.

Osborn, Alex S (1989). Development of public talents, innovation and creativity (Translation: Hassan Ghassemzadeh). Niloufar Publications.

Orai and Yazdani (2007). Management of trust, p88.

Sarafizadeh, Asghar (1951). IT in the organization (Compilation by: Asghar Sarafizadeh, 2009. Tehran: Mir.

Zareimatin, Hassan (2004). Creativity and innovation.Knowledge of Management, no24.

Zargar, Mahmoud (2009). Principles of IT. Tehran.

[In Latin]

Kline, Rex B. (2010). Principles and Practice of Structural Equation Modeling, Series Editor's Note by Todd D. Little, The Guilford press, New York London

Luthans, Fred (2009), "Organizational Behavior", Sixth Edition, USA 